\title{
Editorial
}

Int Neurourol J 2012;16:55-56

http://dx.doi.org/10.5213/inj.2012.16.2.55

pISSN 2093-4777 · eISSN 2093-6931

\section{Adult Neurological Handicap: New Insight from Neurogenesis}

\author{
Khae Hawn Kim \\ Associate Editor \\ Department of Urology, Gachon University Gil Medical Center, Incheon, Korea \\ E-mail: kimcho99@gilhospital.com
}

Neural stem cells were first applied to the urological field through intraspinal transplantation for the recovery of voiding dysfunction in provocative animal research [1], which was then developed further by many researchers in collaboration with several stem cell technologies. Extraordinary interest currently exists in the treatment of degenerative neuronal and bone diseases. This has been generated partly by commercial interest and patients' and researchers' increased awareness and expectations and partly by the advent of great potential for stem cells to treat various neuronal diseases that affect the human body.

Just 10 years ago, there was no way to help people who suffered from voiding dysfunction following brain damage. At present, such injuries are being tried to be improved by grafting new nerve cells over the damaged tissue. Although it may take more time to find cures for other neurological disorders, we will be upbeat about finding a feasible treatment for neurourologic diseases including neuropathic bladder.

In recent years, there has been an increased awareness of the importance of cell proliferation and neurogenesis in the adult brain. Newly generated neurons in the hippocampal dentate gyrus improve or maintain learning and memory functions [2]. Neurogenesis in the adult hippocampus is known to be decreased by various factors, such as aging, irradiation, trauma, and stress [3]. In particular, aging is a potent factor causing a decrease of neurogenesis. Kuhn et al. [4] reported that the production rate of new cells in the hippocampal dentate gyrus is dramatically decreased in aged animals. It has been suggested that an age-related reduction of neurogenesis is due to reduced neurotrophic stimulation. Brain-derived neurotrophic factor is involved in the age-related decline of neurogenesis, and the level of nerve growth factor is also decreased with age [5]. Apoptosis in the hippocampus also affects memory functions. Although apoptosis plays a crucial role in the adult dentate gyrus by preventing excessive growth of the granule cells, neuronal apoptosis in the cortex and hippocampus changes learning and memory, and excessive neuronal apoptosis in the hippocampus contributes to dysfunction of the central nervous system [6].

Why is this seemingly notional discussion important? There are two reasons. First, many urologic diseases carry a narrow diagnostic and therapeutic authority, which may be translated into treatment without a proper consideration of age-related comorbidity. Currently, neurourologic diseases comprise a progressive, age-related, non-sex-specific, non-organ-specific group of symptoms that affect both men and women. Secondly, lower urinary tract symptoms are highly prevalent in patients with advanced degenerative neurologic diseases. More than $50 \%$ of patients have severe bladder symptoms, most frequently symptoms of overactive bladder. Furthermore, poor prognosis of the urologic intervention is associated with a disturbance of cognitive functions, such as learning and memory [7].

We need to take a broader view of neurogenesis, recognizing that this integrated approach to urologic patients reflects our contemporary recognition of the lower urinary tract as an integrated functional unit, and to acknowledge the limitations of neurourology as a sole investigative, diagnostic, and therapeutic modality for spinal cord injury and degenerative brain diseases. 


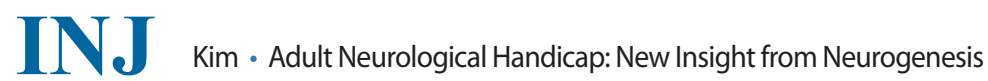

Clearly, by acquiring a deeper understanding of neuronal cell proliferation and/or adult neurogenesis, we hope to develop better tools for the assessment of neurourology and relevant elderly-patient-related outcomes. We also need to increase investigation and awareness regarding degenerative brain diseases and associated urologic comorbidities to improve the current management of the lower urinary tract in aged patients.

\section{REFERENCES}

1. Mitsui T, Kakizaki H, Tanaka H, Shibata T, Matsuoka I, Koyanagi T. Immortalized neural stem cells transplanted into the injured spinal cord promote recovery of voiding function in the rat. J Urol 2003; 170(4 Pt 1):1421-5.

2. van Praag H, Shubert T, Zhao C, Gage FH. Exercise enhances learning and hippocampal neurogenesis in aged mice. J Neurosci 2005; 25:8680-5.
3. Karten YJ, Olariu A, Cameron HA. Stress in early life inhibits neurogenesis in adulthood. Trends Neurosci 2005;28:171-2.

4. Kuhn HG, Dickinson-Anson H, Gage FH. Neurogenesis in the dentate gyrus of the adult rat: age-related decrease of neuronal progenitor proliferation. J Neurosci 1996;16:2027-33.

5. Hattiangady B, Rao MS, Shetty GA, Shetty AK. Brain-derived neurotrophic factor, phosphorylated cyclic AMP response element binding protein and neuropeptide $\mathrm{Y}$ decline as early as middle age in the dentate gyrus and CA1 and CA3 subfields of the hippocampus. Exp Neurol 2005;195:353-71.

6. Sun XQ, Xu ZP, Zhang S, Cao XS, Liu TS. Simulated weightlessness aggravates hypergravity-induced impairment of learning and memory and neuronal apoptosis in rats. Behav Brain Res 2009;199:197202.

7. Mattson MP, Magnus T. Ageing and neuronal vulnerability. Nat Rev Neurosci 2006;7:278-94. 